\title{
Association between egg consumption and elevated fasting glucose prevalence in relation to dietary patterns in selected group of Polish adults
}

Anna Czekajło-Kozłowska' ${ }^{1}$ Dorota Różańska ${ }^{1 *}$ (D) Katarzyna Zatońska², Andrzej Szuba ${ }^{3}$ and Bożena Regulska-llow ${ }^{1}$

\begin{abstract}
Background: The safety of high egg intake in view of its impact on glucose metabolism remains inconclusive. The aim of the study was to assess the relationship between egg intake, dietary patterns and elevated fasting glucose (FG) level in a selected group of Polish adults.

Methods: The study group consisted of 1630 adults who participated in the Polish arm of the Prospective Urban Rural Epidemiological Study. Dietary intake, including egg intake, was assessed based on the data from the Additional file 2 Food Frequency Questionnaire previously validated for the population of Lower Silesia. DPs were derived using principal component analysis. FG levels $\geq 100 \mathrm{mg} / \mathrm{dl}$ were considered elevated. Subjects who used antidiabetic drugs were included in the group with elevated FG levels.

Results: Egg consumption increased in higher quartiles of "Western" and "traditional" DPs in both men and women $(p<0.0001)$. In a crude model each $10 \mathrm{~g}$ of eggs consumed per day was associated with 7\% increased risk (OR 1.07; $95 \% \mathrm{Cl}: 1.01-1.15)$ of elevated glucose level in the overall group and 10\% increased risk (OR 1.10; 95\% Cl: 1.01-1.21) of elevated glucose level in the group of men. Men who consumed at least five eggs per week had higher risk for elevated FG level compared to men who consumed at most one egg per week (OR 1.79; 95\% Cl 1.13-2.84), but this relationship became insignificant when the data were adjusted for DPs. In the group of women no association between egg intake and elevated FG level was observed.
\end{abstract}

Conclusions: Higher egg intake may be associated with the overall unhealthy dietary habits, which is why the number of eggs consumed daily should not be considered an independent risk factor for elevated fasting glucose level.

Keywords: Egg intake, Fasting glucose, Dietary patterns, PURE study, Food frequency questionnaire

\section{Introduction}

Eggs are important source of protein and nutrients in the daily diet. An egg weighing $50 \mathrm{~g}$ fulfills $12 \%$ of daily protein requirement and contains relatively high amounts of monounsaturated fatty acids, iron, zinc, vitamin $A$ and vitamin $B_{12}$. However, egg yolks are also a source of cholesterol and saturated fatty acids (SFA). Two eggs contain $360 \mathrm{mg}$ of cholesterol and $3 \mathrm{mg}$ of SFA which provide about $1,4 \%$ of average daily energy

\footnotetext{
* Correspondence: dorota.rozanska@umed.wroc.pl

${ }^{1}$ Department of Dietetics, Wroclaw Medical University, Parkowa 34, 51-616

Wrocław, Poland

Full list of author information is available at the end of the article
}

intake [1]. The content of the last two components in egg yolk is actually the reason for numerous controversies about frequent egg consumption. In fact, despite many studies conducted on various populations, the association between eggs or dietary cholesterol intake and cardiovascular risk factors remains inconclusive. It seems that SFA, rather than dietary cholesterol, are responsible for elevated blood lipid level [2]. Nevertheless, the effect of cholesterol consumption may depend on individual predispositions and may be related to current health status and genetic factors [3].

Dietary guidelines concerning the recommended cholesterol intake has been changed over the years. In 2006 
American Heart Association recommended to consume at most $300 \mathrm{mg}$ of dietary cholesterol per day [4]. However, in "2007 European Guidelines on cardiovascular disease prevention" and in "2015 - 2020 Dietary Guidelines for Americans" no recommendation for dietary cholesterol intake was mentioned [5, 6]. Current Polish recommendations also do not set up the upper limits for cholesterol intake but emphasize the need to substitute food products rich in SFA and cholesterol by those containing unsaturated fatty acids. According to the Polish authors, healthy individuals with normal cholesterol level in blood may thus consume up to seven eggs per week. However, for subjects with T2DM (type 2 diabetes mellitus) the recommendations are more restrictive, and it is suggested to limit egg intake up to two per week [7]. Overall dietary cholesterol restriction is advised for diabetic patients [8].

The safety of high egg intake in view of its impact on glucose metabolism was analyzed in many studies. Djoussé et al. [9] in a prospective study of 20,703 men from the Physicians' Health Study and 36,295 women from the Women's Health Study observed that daily egg consumption was associated with an increased risk of T2DM (7 eggs per week vs. no egg consumption: OR 1.77; 95\% CI 1.28-2.43 in women and OR 1.58; 95\% CI $1.25-2.01$ in men). In a meta-analysis performed by $\mathrm{Li}$ et al. [10], the relative risk (RR) of diabetes was 1.68 (95\% CI 1.41-2.0) for the highest vs. the lowest egg intake and 1.29 (95\% CI 1.21-1.37) for each 4 per week increment in egg intake. Higher egg consumption was associated with the increased risk of coronary heart disease and mortality in a group of adult diabetics [11-13]. In a meta-analysis of prospective studies based on the US data Djoussé et al. [14] observed no relationship between infrequent egg consumption and T2DM risk, however there was a modest elevated risk of T2DM among individuals consuming $\geq 3$ eggs/week. The authors explained that the negative effect of egg consumption may be caused by trimethylamine- $\mathrm{N}$-oxide (TMAO) but there was no enough evidence to confirm that theory. Eventually it was suggested that not only egg consumption, but also dietary patterns should be taken into account in future analysis.

Dietary pattern analysis is used in order to assess the cumulative effect of the single components of the diet on health $[15,16]$. Due to various interactions between individual components of the diet, different effect of intake of, for instance, seven eggs per week should be observed in individuals having healthy dietary habits (i.e. consuming lots of vegetables, fruits and whole grains) and those having overall unhealthy diet. Suliga et al. [17] conducted a study to derive the main DPs among Polish adults and to evaluate the association between these patterns and metabolic syndrome and its components. The authors found that higher intake of refined grains, potatoes, sugar and sweets ("Traditional-carbohydrate" DP) was associated with a higher risk of abdominal obesity and elevated triglyceride level, whereas a "Westernized" DP was related to hyperglycemia.

Due to the above-mentioned considerations, the effect of egg intake on glucose metabolism should not be assessed separately but as a part of overall diet. The aim of the study was to assess the relationship between egg consumption and elevated fasting glucose (FG) levels according to the DPs derived in the study group.

\section{Methods}

\section{Study population}

Prospective Urban Rural Epidemiological (PURE) Study is an international cohort study which at baseline involved 153,996 adults from 17 countries with different income levels [18]. Individuals were recruited to the Polish arm of the PURE Study through the radio and television announcements. The study was conducted between 2007 and 2009. The general inclusion criteria were as follows: age 35-70 years, permanent residence in the urban or rural areas of the Lower Silesian Voivodeship and daily energy intake between 500 and $4000 \mathrm{kcal}$. Out of 2025 individuals who were involved in the overall Polish arm of the baseline PURE Study, 1630 adults (1041 women and 589 men) had complete medical data on analyzed factors and were included in the study group. Flow chart of sample collection was presented in Fig. 1. The comparison of the study group and the drop out group was presented in the Additional file 1: Table S1.

\section{Blood glucose}

Blood glucose level was measured in venous blood samples after an overnight fast using the Ascensia Entrust Glucometer (Bayer, Germany). Fasting glucose levels $\geq 100 \mathrm{mg} / \mathrm{dl}$ were considered elevated. Participants who used antidiabetic drugs were automatically included in the group with elevated FG levels.

\section{Eggs consumption and dietary patterns assessment}

As the average consumption of different food products is culture-dependent, dietary intake was evaluated using the data from the Additional file 2 Food Frequency Questionnaire (FFQ) previously validated for the population of Lower Silesia [19]. Frequency of consumption of 154 food products and dishes in 12 months preceding the study was recorded in nine different categories: "never or less than once a month", "1-3 times a month", "once a week", "2-4 times a week", "5-6 times a week", "once a day", "2-3 times a day", "4-5 times a day" or "more than 6 times a day". "Album of photographs of food products and dishes" was used in order to estimate the average portion sizes of consumed foods [20]. 


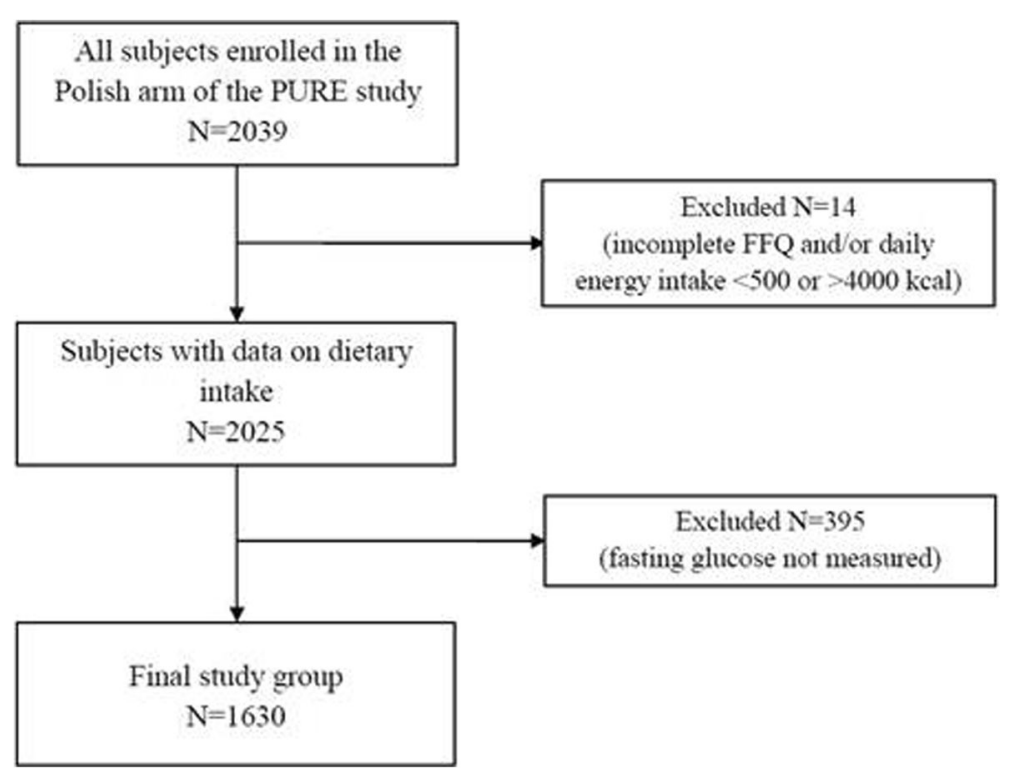

Fig. 1 Flow chart of sample collection

Dietary patterns were identified in the study group a posteriori using a principal component analysis with varimax rotation. This statistical method aims to identify the main patterns of food consumption, explaining as much of the data variance as possible. Food products from the FFQ were categorized into 22 groups based on their nutritional value and usual consumption purpose. Products that are not a source of energy, such as unsweetened coffee and tea, were not included in the analysis. Characteristics of the food groups were summarized in Table 1.

Due to the fact that in the preliminary analysis eggs did not have high factor loadings for any of identified DPs (so their consumption was not particularly characteristic for any of the dietary patterns), they were not included in the final analysis. The number of patterns was determined based on the eigen values (Kaiser's criterion), the scree plot and the interpretability of derived factors. As a cut-off point were accepted factor loadings higher than 0.50 .

\section{Statistical analysis}

All statistical analyses were conducted using the Statistica software version 12.0 PL (Statsoft Inc., USA). Mean nutritional value was estimated in the diets of studied men and women. Based on the obtained factor scores, for each of the identified DPs study individuals were divided into quartiles or included into one of two following groups: below the median $(<\mathrm{Me})$ or equal/above the median $(\geq \mathrm{Me})$ for the gender. The differences in usual egg intake between the quartiles of dietary patterns and categories of egg intake were assessed using the ANOVA Kruskal-Wallis test. Chi-square test for trend was used to evaluate the relationship between usual egg intake and the prevalence of elevated FG level with reference to identified DPs. In order to assess the ORs for the elevated FG level occurrence according to egg intake, logistic regression was applied. Consumption of no more than one egg per week was considered the reference category of egg intake. Six models were created for the overall group and separately for women and men: first model was based on the crude data, while other models were adjusted for age, body mass index (BMI), percentage of energy from SFA, the intake of simple sugars per $1000 \mathrm{kcal}$ and factor scores for identified dietary patterns. The level of statistical significance for all analyses was set at $\alpha=0.05$.

\section{Results}

The general characteristics of the study group were presented in Table 2. Mean age and percentage of individuals with elevated blood glucose level was similar in the groups of women and men (54.7 \pm 9.8 years vs. $54.1 \pm$ 10.0 years and $37.6 \%$ vs. $41.6 \%$, respectively). Men consumed more eggs per day in comparison with women $(18.1 \pm 18.5 \mathrm{~g}$ vs. $14.8 \pm 12.6 \mathrm{~g} ; p=0.0084)$. The percentage of individuals who consumed $\leq 1 \mathrm{egg} /$ week was similar in both groups. Significantly more women than men consumed $2-4$ eggs/week $(p=0.0077)$, but significantly more men than women consumed $\geq 5$ eggs/week ( $p<$ $0.0001)$. No difference in energy intake and percentage of energy from SFA was found between gender groups. The intake of cholesterol was higher in the group of men compared to women $(302.5 \pm 147.7 \mathrm{mg}$ vs. $280.6 \pm$ $130.2 \mathrm{mg} ; p=0.0130$ ), however after adjustment for energy intake no such relationship was found. Women 
Table 1 Characteristics of the food groups used in the dietary pattern analysis

\begin{tabular}{|c|c|}
\hline Food group & Products \\
\hline Milk and low-fat dairy & $\begin{array}{l}\text { Low-fat milk, 1-2\% fat [1], milk, 3.2\% fat [2], buttermilk, 0.5\% fat [3], cocoa with milk [4], cottage cheese [6], quark, fresh } \\
\text { cheese [10], low-fat yoghurt [11], yogurt, 2-8\% fat [12], kefir [13] }\end{array}$ \\
\hline $\begin{array}{l}\text { High-fat cheese and } \\
\text { cream }\end{array}$ & $\begin{array}{l}\text { Feta cheese [5], hard cheese [7], cheese, "fromage" naturel [8], cheese, Edam type, fat [9], cream, 12\% fat [14], cream, 18\% fat } \\
\text { [15] }\end{array}$ \\
\hline Fats & Margarine, soft [16], butter [18], lard [19], Finea/Masmix [20], mayonnaise [148] \\
\hline Fruits & $\begin{array}{l}\text { Apple [21], banana [22], grapefruit [23], grapes [24], tangerine [25], strawberries [26], kiwi fruit [27], lemon [28], orange [29], } \\
\text { peach [30], pear [31], plum [32], raspberries [33] }\end{array}$ \\
\hline Vegetables & $\begin{array}{l}\text { Beans, white (boiled) [34], beets, cooked [35], broccoli, green [36], cabbage, red (raw) [37], cabbage, Shantung [38], cabbage, } \\
\text { white (raw) [39], cabbage, white (boiled) [40], carrot (fresh) [41], carrot (boiled) [42], cauliflower (raw) [43], cauliflower (boiled } \\
\text { with butter) [44], chives [45], cucumber (raw) [46], garlic (raw) [47], lettuce [48], mushroom (fried) [49], onion (raw) [50], } \\
\text { parsley, leaves [51], horseradish [52], pepper (cooked) [53], pepper, red (raw) [54], radish [58], tomato (raw) [59], tomato } \\
\text { (cooked) [60], tomato sauce [61], spinach (cooked) [62], squash, summer (cooked) [63], string beans (boiled) [64], sweet corn } \\
\text { (canned, drained) [65], peas green (canned, drained) [66], shantung cabbage, salad with mayonnaise [115], sauerkraut salad } \\
\text { [116], lettuce with sour cream salad [118] }\end{array}$ \\
\hline Chips & Potato (French fried) [55] \\
\hline Potatoes & Potato (boiled) [56], potato (mashed) [57] \\
\hline Red meat & $\begin{array}{l}\text { Beef steaks [68], pork, belly (no bone, boiled) [79], pork cutlets (breaded, fried) [81], organ meat (liver, tongue, heart) [89], } \\
\text { beef and pork minced cutlets (fried) [100] }\end{array}$ \\
\hline $\begin{array}{l}\text { Processed red/mixed } \\
\text { meat }\end{array}$ & $\begin{array}{l}\text { Beef, ham (cooked) [69], Frankfurter/Hotdog [76], luncheon meat (pork) [77], pork ham [80] sausage Slaska (pork, cooked) } \\
\text { [82], sausage Krakowska (pork and beef) [83], sausage Biala (pork) [84], sausage Szynkowa (turkey) [87], Head Cheese, white } \\
\text { and black [88] chicken pate (canned) [104] }\end{array}$ \\
\hline Low-fat poultry & Chicken without skin (cooked/fried) [73], turkey (roasted) [86] \\
\hline $\begin{array}{l}\text { High-fat/processed } \\
\text { poultry }\end{array}$ & Chicken fillets (breaded, fried) [70], chicken ham [71], chicken with skin (cooked/fried) [72], turkey, ham [85] \\
\hline Fish & Cod fillets (breaded and fried) [74], herring in cream [75], mackerel (smoked) [78] \\
\hline Unrefined grains & $\begin{array}{l}\text { Rye, brown bread [92], wheat-rye bread with sunflower seeds [96], pasta (cooked) [98], buckwheat groats (boiled) [102], pearl } \\
\text { barley groats (boiled) [105], soup, milk with rolled oats [109] }\end{array}$ \\
\hline Refined grains & $\begin{array}{l}\text { Wheat bread [90], rice (boiled) [91], wheat rolls (kajzerki) [93], wheat rolls (wroclawskie) [94], wheat-rye bread/white bread } \\
\text { [95], cold cereal (cornflakes) [97] }\end{array}$ \\
\hline Mixed dishes & $\begin{array}{l}\text { Baked beans with meat [99], cabbage leaves, stuffed [103], Polish dumplings, with meat [113], sauerkraut with sausage and } \\
\text { meat (bigos, stewed) [114], dumplings with potato filling (Ruskie, boiled) [117], vegetable salad (cooked with mayonnaise) } \\
\text { [119] }\end{array}$ \\
\hline Soups & $\begin{array}{l}\text { Broth [101], soup with vegetables [106], soup, Krupnik with pearl barley groats [107], soup, Zurek sour rye [108], soup, tomato } \\
\text { [110], soup, sauerkraut [111], soup, white bean [112] }\end{array}$ \\
\hline Juices & $\begin{array}{l}\text { Orange juice [120], carrot juice [122], apple juice [123], grapefruit juice [124], blackcurrant juice [125], multifruit juice from } \\
\text { Polish fruits [126], multifruit juice from exotic fruits [127] }\end{array}$ \\
\hline Beverages & Raspberry juice [121], fruits drink [128], soft drink (regular) [129], soft drink (low calorie) [130] \\
\hline Alcohol & Beer [134], red wine [135], vodka [136] \\
\hline Sweets & $\begin{array}{l}\text { Ice cream [17], milk chocolate [137], bitter chocolate [138], biscuits [139], yeast cake [140], short-cake [141], gingerbread cake } \\
\text { [142], sponge cake [143], cheesecake (Krakowski) [144], halva with vanilla [146], drops [147], sweets [151] }\end{array}$ \\
\hline Sugar and honey & Honey [145], sugar [152] \\
\hline Nuts, seeds and raisins & Nuts [149], raisins, dried [150], seeds [153], walnuts [154] \\
\hline
\end{tabular}

Number in bracket refers to the item number in the Food Frequency Questionnaire (available in Additional file 2)

consumed more simple sugars per $1000 \mathrm{kcal}$ than men $(46.7 \pm 12.7$ vs. $42.1 \pm 12.7 ; p<0.0001)$.

Three main DPs were identified in the study group. "Western" DP was associated with high factor loadings for fats (0.65), sweets (0.62), refined grains (0.60), highfat cheese and cream (0.60), processed red/mixed meat (0.59) and sugar \& honey (0.55), "prudent" pattern was related to high consumption of fruits $(0.71)$, vegetables
(0.66), nuts, seeds \& raisins (0.61) and milk and low-fat dairy (0.52), while "traditional" pattern was linked with high intake of mixed dishes (0.75), soups (0.69), red meat (0.61) and fish (0.59). Together derived DPs explained $36.7 \%$ of the total variance. The factor-loading matrix for the identified DPs was presented in Table 3.

Both in the group of women and men, egg intake increased in higher quartiles of "Western" and 
Table 2 General characteristics of the study group $(n=1630)$

\begin{tabular}{|c|c|c|c|}
\hline Variable & Women $(n=1041)^{*}$ & Men $(n=589)^{*}$ & $p^{\#}$ \\
\hline Age [years] & $54.7 \pm 9.8$ & $54.1 \pm 10.0$ & NS \\
\hline $\mathrm{BMI}\left[\mathrm{kg} / \mathrm{m}^{2}\right]$ & $27.9 \pm 5.4$ & $28.8 \pm 4.7$ & $<0.0001$ \\
\hline$\%$ of individuals with blood glucose $\geq 100 \mathrm{mg} / \mathrm{dl}$ & 37.6 & 41.6 & NS \\
\hline Egg consumption [g/day] & $14.8 \pm 12.6$ & $18.1 \pm 18.5$ & 0.0084 \\
\hline$\%$ of individuals who consume $\leq 1 \mathrm{egg} /$ week & 45.9 & 43.8 & NS \\
\hline$\%$ of individuals who consume $2-4$ eggs/week & 45.3 & 38.5 & 0.0077 \\
\hline$\%$ of individuals who consume $\geq 5$ eggs/week & 8.7 & 17.7 & $<0.0001$ \\
\hline Energy intake [kcal/day] & $2079.0 \pm 757.1$ & $2130.9 \pm 718.3$ & NS \\
\hline SFA intake [\% of energy] & $12.5 \pm 3.4$ & $12.3 \pm 4.5$ & NS \\
\hline Cholesterol intake [mg/day] & $280.6 \pm 130.2$ & $302.5 \pm 147.7$ & 0.0130 \\
\hline Cholesterol intake $[\mathrm{mg} / 1000 \mathrm{kcal} /$ day] & $134.6 \pm 37.7$ & $139.9 \pm 42.7$ & NS \\
\hline Simple sugars intake $[\mathrm{g} / 1000 \mathrm{kcal} /$ day] & $46.7 \pm 12.7$ & $42.1 \pm 12.7$ & $<0.0001$ \\
\hline
\end{tabular}

* - values are mean \pm standard deviation except for percentage of individuals with elevated blood glucose level and percentage of individuals in particular categories of egg intake; ${ }^{\#}$ - U-Mann Whitney test for quantitative variables and $\mathrm{X}^{2}$ test for qualitative variables; BMI - body mass index; SFA - saturated fatty acids; NS - no statistically significant difference

Table 3 Factor-loading matrix for dietary patterns identified in the study group ${ }^{*}$

\begin{tabular}{|c|c|c|c|}
\hline Variable & "Western" DP & "Prudent" DP & "Traditional" DP \\
\hline Fats & 0.65 & & \\
\hline Sweets & 0.62 & & \\
\hline Refined grains & 0.60 & & \\
\hline High-fat cheese and cream & 0.60 & & \\
\hline Processed red/mixed meat & 0.59 & & \\
\hline Sugar \& honey & 0.55 & & \\
\hline \multicolumn{4}{|l|}{ Chips } \\
\hline \multicolumn{4}{|l|}{ Juices } \\
\hline Fruits & & 0.71 & \\
\hline Vegetables & & 0.66 & \\
\hline Nuts, seeds and raisins & & 0.61 & \\
\hline Milk and low-fat dairy & & 0.52 & \\
\hline \multicolumn{4}{|l|}{ Unrefined grains } \\
\hline \multicolumn{4}{|l|}{ Beverages } \\
\hline Mixed dishes & & & 0.75 \\
\hline Soups & & & 0.69 \\
\hline Red meat & & & 0.61 \\
\hline Fish & & & 0.59 \\
\hline \multicolumn{4}{|l|}{ Low-fat poultry } \\
\hline \multicolumn{4}{|l|}{ High-fat/processed poultry } \\
\hline \multicolumn{4}{|l|}{ Potatoes } \\
\hline \multicolumn{4}{|l|}{ Alcohol } \\
\hline Percentage of variance explained (\%) & 19.82 & 10.57 & 6.27 \\
\hline
\end{tabular}

\footnotetext{
* the absolute values of factor loadings $\geq 0.5$ were shown; DP - dietary pattern
} 
Table 4 Egg intake ( $g$ per day) in quartiles of derived dietary patterns $(X \pm S D)$ in group of women and men

\begin{tabular}{|c|c|c|c|c|c|c|c|}
\hline \multirow[t]{2}{*}{ Group } & \multirow{2}{*}{$\begin{array}{l}\text { Q } \\
\text { of } \\
\text { DP }\end{array}$} & \multicolumn{2}{|l|}{ "Western" DP } & \multicolumn{2}{|l|}{ "Prudent" DP } & \multicolumn{2}{|l|}{ "Traditional" DP } \\
\hline & & $\begin{array}{l}\text { Egg intake (g/day) } \\
X \pm S D\end{array}$ & $p^{*}$ & $\begin{array}{l}\text { Egg intake (g/day) } \\
X \pm S D\end{array}$ & $p^{*}$ & $\begin{array}{l}\text { Egg intake (g/day) } \\
X \pm S D\end{array}$ & $p^{*}$ \\
\hline \multirow{4}{*}{$\begin{array}{l}\text { Women } \\
(n=1041)\end{array}$} & Q1 & $11.9 \pm 11.9$ & \multirow[t]{4}{*}{$<0.0001$} & $13.3 \pm 9.8$ & \multirow[t]{4}{*}{ NS } & $10.8 \pm 9.2$ & \multirow[t]{4}{*}{$<0.0001$} \\
\hline & Q2 & $13.4 \pm 12.0$ & & $15.6 \pm 13.2$ & & $14.3 \pm 11.5$ & \\
\hline & Q3 & $14.8 \pm 12.8$ & & $14.8 \pm 13.4$ & & $16.7 \pm 11.7$ & \\
\hline & Q4 & $19.0 \pm 12.8$ & & $14.8 \pm 13.6$ & & $17.4 \pm 16.0$ & \\
\hline \multirow{4}{*}{$\begin{array}{l}\text { Men } \\
(n=589)\end{array}$} & Q1 & $11.4 \pm 14.7$ & \multirow[t]{4}{*}{$<0.0001$} & $20.4 \pm 21.8$ & \multirow[t]{4}{*}{ NS } & $12.9 \pm 12.9$ & \multirow[t]{4}{*}{$<0.0001$} \\
\hline & Q2 & $14.7 \pm 13.2$ & & $17.8 \pm 17.9$ & & $16.3 \pm 15.3$ & \\
\hline & Q3 & $18.5 \pm 16.4$ & & $18.1 \pm 19.2$ & & $20.5 \pm 18.6$ & \\
\hline & Q4 & $27.5 \pm 23.7$ & & $16.0 \pm 13.9$ & & $22.5 \pm 23.8$ & \\
\hline \multirow{4}{*}{$\begin{array}{l}\text { Overall } \\
(n=1630)\end{array}$} & Q1 & $11.7 \pm 12.1$ & \multirow[t]{4}{*}{$<0.0001$} & $16.6 \pm 16.6$ & \multirow[t]{4}{*}{ NS } & $10.9 \pm 9.5$ & \multirow[t]{4}{*}{$<0.0001$} \\
\hline & Q2 & $14.0 \pm 13.3$ & & $15.8 \pm 15.5$ & & $15.7 \pm 13.6$ & \\
\hline & Q3 & $16.0 \pm 13.5$ & & $15.8 \pm 12.5$ & & $17.6 \pm 14.6$ & \\
\hline & Q4 & $22.2 \pm 18.5$ & & $15.8 \pm 15.3$ & & $19.7 \pm 19.5$ & \\
\hline
\end{tabular}

" - ANOVA Kruskal-Wallis test; X $\pm S D$ - mean \pm standard deviation; DP - dietary pattern; Q1, Q2, Q3, Q4 - quartile 1, 2, 3, 4; NS - no statistically significant difference

“traditional" DPs $(p<0.0001)$. No association was observed with reference to "prudent" pattern. The similar association was observed in the overall study group (Table 4).

Table 5 shows the comparison of dietary cholesterol intake and percentage of energy from SFA depending on habitual egg intake in the study group. Increased egg intake was associated with higher cholesterol intake per $1000 \mathrm{kcal}$ and higher percentage of energy from SFA in the overall study group and in both men and women $(p<0.0001)$. When the intake of SFA and cholesterol from eggs were not taken into account in the analysis the results remained similar. The intake of cholesterol increased from $99.5 \pm$ $25.6 \mathrm{mg} / 1000 \mathrm{kcal}$ in the group who consumed $\leq 1$ egg per week to $123.6 \pm 27.4 \mathrm{mg} / 1000 \mathrm{kcal}$ in the group who consumed $\geq 5$ eggs per week $(p<0.0001)$. The percentage of energy from SFA increased from $11.6 \pm 3.4 \%$ to $13.5 \pm$ $3.4 \%(p<0.0001)$, respectively.

In the group of women egg intake was not associated with the prevalence of elevated FG level, regardless of dietary pattern. Instead, higher prevalence of elevated fasting glucose level was observed in the group of men who had high factor scores for "Western" or "traditional" DPs ( $\geq$ Me for the group; $p$ for trend 0.0403 and 0.0045 , respectively). Egg consumption was not associated with elevated FG in the group of men who had overall "prudent" DP ( $\geq$ Me for the group; $p$ for trend 0.2060) (data not shown in tables).

The ORs and 95\% confidence intervals of the elevated glucose level occurrence in relation to egg consumption in the study group were presented in Table 6 . In a model based on the crude data, men who consumed at least five eggs per week had higher odds ratio for elevated FG level compared to men who consumed at most one egg per week (OR 1.79; 95\% CI 1.13-2.84). The relationship remained statistically significant after adjustment for age and BMI (model 2: OR 1.71; 95\% CI 1.05-2.77) and age, BMI, percentage of energy from SFA and the intake of simple sugars per $1000 \mathrm{kcal}$ (model 3: OR 1.66; 95\% CI 1.01-2.74). However, when the data were adjusted also for the factor scores for derived dietary patterns ("Western" DP - model 4, "prudent" DP - model 5 and "traditional" DP - model 6), no relationship between the category of egg consumption and elevated FG level occurrence was observed. In the group of women, egg intake was not linked with the elevated FG level in any of the studied models. Taking into account the overall study group, in a model based on the crude data, the consumption of at least five eggs per week was associated with higher odds ratio for elevated FG level compared to the consumption of at most one egg per week (OR 1.39; 95\% CI 1.03-1.89), however the relationship did not remain statistically significant after adjustment for confounding variables. For each increase in egg intake of $10 \mathrm{~g} /$ day (crude data) in the group of men there was a $10 \%$ increased risk (OR 1.10; 95\% CI 1.01-1.21) of elevated glucose level, while in the overall study group there was a 7\% increased risk (OR 1.07; 95\% CI 1.011.15) of elevated glucose level. After adjustment for confounding variables the relationships did not remain statistically significant.

\section{Discussion}

Three main DPs were identified in the study group: "Western", "prudent" and "traditional". Egg intake increased in higher quartiles of "Western" and "traditional" DPs, but no association was observed with reference to "prudent" pattern. The association between prevalence 


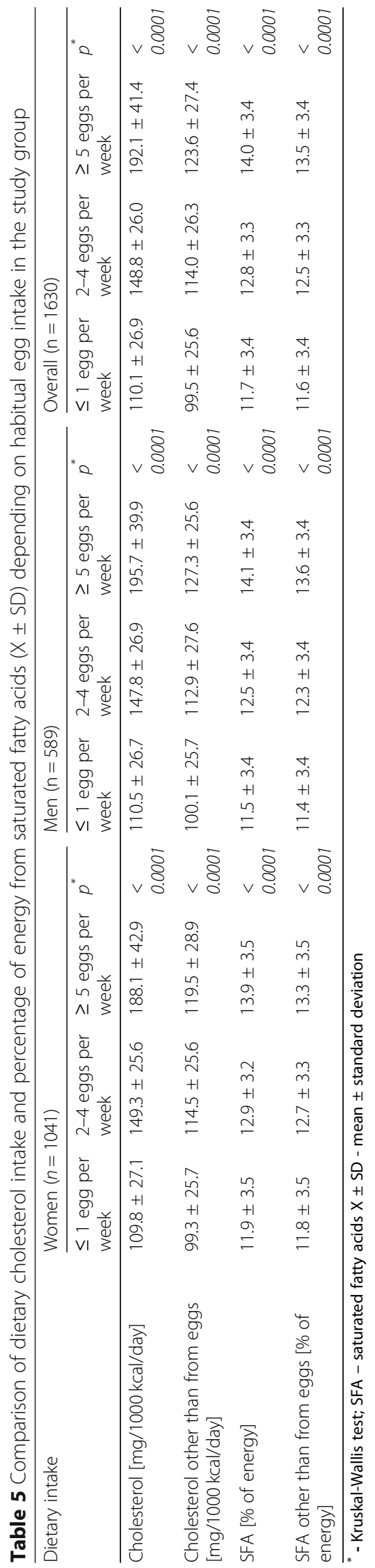


Table 6 The odds ratio (OR) and 95\% confidence interval (95\% Cl) of the elevated glucose level ( $\geq 100$ mg/dl) in relation to habitual egg consumption in the study group

\begin{tabular}{|c|c|c|c|c|c|c|c|}
\hline \multirow[t]{2}{*}{ Group } & \multirow{2}{*}{$\begin{array}{l}\text { Category of habitual egg } \\
\text { intake }\end{array}$} & \multicolumn{6}{|l|}{ OR $(95 \% \mathrm{Cl})$} \\
\hline & & Model 1 & Model 2 & Model 3 & $\begin{array}{l}\text { Model } 4 \\
\text { (Western DP) }\end{array}$ & $\begin{array}{l}\text { Model } 5 \\
\text { (Prudent DP) }\end{array}$ & $\begin{array}{l}\text { Model } 6 \text { (Traditiona } \\
D P \text { ) }\end{array}$ \\
\hline \multirow{4}{*}{$\begin{array}{l}\text { Women }(n= \\
1041)\end{array}$} & $\leq 1 \mathrm{egg} /$ week & 1.00 & 1.00 & 1.00 & 1.00 & 1.00 & 1.00 \\
\hline & 2-4 eggs/week & $\begin{array}{l}0.92(0.71- \\
1.21)\end{array}$ & $\begin{array}{l}0.87(0.66- \\
1.14)\end{array}$ & $\begin{array}{l}0.87(0.66- \\
1.15)\end{array}$ & $\begin{array}{l}0.81(0.61- \\
1.07)\end{array}$ & $\begin{array}{l}0.87(0.66- \\
1.15)\end{array}$ & $0.86(0.65-1.13)$ \\
\hline & $\geq 5$ eggs/week & $\begin{array}{l}1.06(0.67- \\
1.67)\end{array}$ & $\begin{array}{l}1.06(0.66- \\
1.71)\end{array}$ & $\begin{array}{l}1.06(0.65- \\
1.71)\end{array}$ & $\begin{array}{l}0.99(0.62- \\
1.59)\end{array}$ & $\begin{array}{l}1.09(0.67- \\
1.78)\end{array}$ & $1.01(0.65-1.56)$ \\
\hline & $\begin{array}{l}10 \mathrm{~g} \text { increased egg intake/ } \\
\text { day }\end{array}$ & $\begin{array}{l}1.03(0.93- \\
1.14)\end{array}$ & $\begin{array}{l}1.02(0.92- \\
1.13)\end{array}$ & $\begin{array}{l}1.02(0.92- \\
1.13)\end{array}$ & $\begin{array}{l}1.00(0.90- \\
1.10)\end{array}$ & $\begin{array}{l}1.02(0.92- \\
1.14)\end{array}$ & $1.01(0.91-1.12)$ \\
\hline \multirow[t]{4}{*}{ Men $(n=589)$} & $\leq 1$ egg/week & 1.00 & 1.00 & 1.00 & 1.00 & 1.00 & 1.00 \\
\hline & 2-4 eggs/week & $\begin{array}{l}1.17(0.81- \\
1.69)\end{array}$ & $1.07(0.73-1.57$ & $\begin{array}{l}1.06(0.72- \\
1.56)\end{array}$ & $\begin{array}{l}0.97(0.65- \\
1.44)\end{array}$ & $\begin{array}{l}1.07(0.72- \\
1.57)\end{array}$ & $1.05(0.71-1.55)$ \\
\hline & $\geq 5$ eggs/week & $\begin{array}{l}1.79(1.13- \\
2.84)\end{array}$ & $\begin{array}{l}1.71(1.05- \\
2.77)\end{array}$ & $\begin{array}{l}1.66(1.01- \\
2.74)\end{array}$ & $\begin{array}{l}1.32(0.77- \\
2.28)\end{array}$ & $\begin{array}{l}1.65(0.99- \\
2.72)\end{array}$ & $1.61(0.97-2.67)$ \\
\hline & $\begin{array}{l}10 \mathrm{~g} \text { increased egg intake/ } \\
\text { day }\end{array}$ & $\begin{array}{l}1.10(1.01- \\
1.21)\end{array}$ & $\begin{array}{l}1.08(0.98- \\
1.19)\end{array}$ & $\begin{array}{l}1.07(0.97- \\
1.18)\end{array}$ & $\begin{array}{l}1.02(0.92- \\
1.13)\end{array}$ & $\begin{array}{l}1.07(0.97- \\
1.18)\end{array}$ & $1.06(0.96-1.17)$ \\
\hline \multirow{4}{*}{$\begin{array}{l}\text { Overall }{ }^{*}(n= \\
1630)\end{array}$} & $\leq 1$ egg/week & 1.00 & 1.00 & 1.00 & 1.00 & 1.00 & 1.00 \\
\hline & 2-4 eggs/week & $\begin{array}{l}1.00(0.97- \\
1.03)\end{array}$ & $\begin{array}{l}0.94(0.75- \\
1.17)\end{array}$ & $\begin{array}{l}0.94(0.75- \\
1.17)\end{array}$ & $\begin{array}{l}0.86(0.68- \\
1.08)\end{array}$ & $\begin{array}{l}0.94(0.75- \\
1.17)\end{array}$ & $0.92(0.74-1.16)$ \\
\hline & $\geq 5$ eggs/week & $\begin{array}{l}1.39(1.03- \\
1.89)\end{array}$ & $\begin{array}{l}1.34(0.96- \\
1.87)\end{array}$ & $\begin{array}{l}1.33(0.94- \\
1.87)\end{array}$ & $\begin{array}{l}1.16(0.82- \\
1.66)\end{array}$ & $\begin{array}{l}1.34(0.95- \\
1.89)\end{array}$ & $1.28(0.90-1.81)$ \\
\hline & $\begin{array}{l}10 \mathrm{~g} \text { increased egg intake/ } \\
\text { day }\end{array}$ & $\begin{array}{l}1.07(1.01- \\
1.15)\end{array}$ & $\begin{array}{l}1.05(0.98- \\
1.13)\end{array}$ & $\begin{array}{l}1.05(0.98- \\
1.12)\end{array}$ & $\begin{array}{l}1.02(0.95- \\
1.10)\end{array}$ & $\begin{array}{l}1.05(0.98- \\
1.13)\end{array}$ & $1.04(0.97-1.12)$ \\
\hline
\end{tabular}

DP - dietary pattern; Model 1 - without adjustment for confounding variables; Model 2 - adjusted for age and body mass index (BMI); Model 3 - adjusted for age, BMI, percentage of energy from saturated fatty acids (SFA) and simple sugars intake/1000 kcal; Model 4 - adjusted for age, BMI, percentage of energy from SFA, simple sugars intake/1000 kcal and factor score for "Western" DP; Model 5 - adjusted for age, BMl, percentage of energy from SFA, simple sugars intake/1000 kcal and factor score for "prudent" DP; Model 6 - adjusted for age, BMI, percentage of energy from SFA, simple sugars intake/1000 kcal and factor score for "traditional" DP; ${ }^{*}$ - all models (exc. Model 1) additionally adjusted for sex

of elevated FG and egg intake was observed only in the group of men with higher adherence to "Western" or "traditional" DPs. Men who consumed at least five eggs per week had higher risk for elevated FG level compared to men who consumed at most one egg per week, but in the models adjusted for the factor scores for dietary patterns, no such relationship was observed.

The dietary risk factors for diabetes include refined grains, sugar-sweetened beverages, fruit juices and red and processed meat [21]. Eggs are also considered a dietary component increasing the risk of T2DM especially due to possible negative effect of TMAO which is formed from dietary choline, naturally found in eggs [14]. However, according to the results of the presented study, the assessment of the association between egg consumption and impaired glucose metabolism should not be based solely on the number of eggs consumed weekly. The most common egg dishes contain products with different nutritional characteristics. Eggs may be used to prepare various fried dishes, cakes and dressings which cannot be recommended in the daily diet due to their nutritional value. It also seems incorrect not to mention the difference in the nutritional value of e.g. scrambled eggs made with olive oil and vegetables and scrambled eggs made with butter and bacon, which results from a significantly different fatty acids profile of these two dishes. Moreover, unhealthy dietary habits are usually related to the excessive adiposity which is the major risk factor for diabetes itself [22]. The question is therefore whether eggs themselves may cause harmful health effects or maybe they are usually consumed as a part of unhealthy dietary pattern.

In the herein study, egg intake increased in higher quartiles of "Western" and "traditional" DPs in both men and women. "Western" pattern was characterized by high consumption of food products considered unhealthy. In other studies, this type of dietary pattern was linked with elevated FG levels or diabetes [23-26]. "Traditional" pattern identified in our study had high factor loadings for various food groups. Some of them contain products highly recommended in the daily diet, such as vegetables, grains and oily fish. However, typical Polish dishes are often prepared with the use of butter or lard, important sources of SFA in the diet [1]. Study individuals who consumed more eggs had higher intake of SFA and cholesterol even when the intake of these nutrients from eggs was not included in the analysis. 
Moreover, it is known that food preparation techniques, including boiling, frying or roasting, may affect the nutritional value of dishes: increase their glycemic index and decrease the content of essential nutrients [27]. Consumption of eggs was not associated with the "prudent" pattern. Obtained results indicate that subjects who consumed more eggs simultaneously had less healthy eating habits so potential metabolic abnormalities could result from their overall dietary habits.

Nevertheless, in the group of women there was no association between the category of egg intake and the elevated FG prevalence neither in the overall group nor in subgroups with the factor scores for the identified dietary patterns below or equal/above the median. Moreover, in the group of women egg consumption was not related to the risk of elevated FG level in any of the created models. Obtained results appear to be consistent with the observations made by Woo et al. [28] who found no association between egg consumption and elevated FG level in a group of adult Korean women. Nonetheless, Shin et al. [29] reported that higher egg consumption was inversely associated with the elevated FG level in women (7 eggs per week vs. < 1 egg per week: OR 0.94; 95\% CI 0.83-0.99).

In the group of men, the prevalence of elevated FG level increased across the categories of egg consumption, however the association remained significant only in men in the subgroups $\geq$ median factor scores for the "Western" and "traditional" DPs. In the group of men who consumed large amounts of eggs but simultaneously had overall healthy dietary habits, egg intake was not linked with elevated FG level. When the logistic regression models were adjusted for the factor scores for the DPs, the increased OR for elevated FG level observed in the crude model in the highest category of egg intake became insignificant, which indicates that in this case the overall eating habits might have played a greater part in the development of this abnormality.

The results of the studies on the relationship between egg intake and elevated FG level among men conducted by other authors are not conclusive. Woo et al. [28] observed that higher egg consumption ( $>3$ eggs per week) was associated with a decreased risk of elevated FG level (RR 0.39; 95\% CI 0.22-0.67). In a study performed by Shin et al. [29] no such relationship was found. Park et al. [30] observed that in a group of individuals who consumed 4-6 eggs per week the OR for elevated FG level was 0.82 (95\% CI $0.72-0.93)$. In this study a gender-stratified statistical analysis was not performed due to a small number of subjects in the categories of egg intake.

Observed differences between results of the studies in both men and women, apart from other lifestyle, socio-economic and genetic factors, may result from different eating habits in various populations. According to the current guidelines, egg may be a part of a healthy DP, as a good source of protein in the diet [6]. However, in some studies eggs were characteristic for unhealthy, usually Western-like dietary patterns, associated with higher risk of hypertriglyceridemia, hypercholesterolemia and obesity [23, 31-34]. In a meta-analysis performed by Jannasch et al. [25] eggs were typical food product for "mainly unhealthy" dietary pattern which was positively associated with T2DM (RR $1.44 ; 95 \%$ CI 1.27-1.62). Although in this study population eggs were not typical for any of the identified patterns in the preliminary analysis, it may be recognized that their consumption together with unhealthy DPs, especially in the group of men, somehow explains obtained results.

Our study has several limitations. Subjects were recruited through radio and television, so the studied group was not a representative sample. Due to the lack of the required data a drop out was higher than $20 \%$ what might have affected the results. As it was a crosssectional study, the causal relationship between egg consumption and elevated FG level could not be assessed and observed relationships should be confirmed in prospective analyses. Another limitation is that we could use only fasting glucose level as a marker of impaired glucose metabolism because it was the only one assessed in the baseline PURE study. However, it is one of the markers most commonly used in epidemiological studies. Nevertheless, the strength of our study is that it was performed in a large group of participants, using standardized methods and country-specific, validated food frequency questionnaire of good quality. Another limitation of our study is the underreporting of habitual food intake especially in men. Although this is a common bias found in nutritional studies, it should be considered when interpreting the results. Patterns identified a posteriori illustrated the actual culture-dependent eating habits of the studied group of subjects. The association between FG level, egg intake and DPs were thus assessed in the light of the interactions between the particular elements of the diet what may provide a new perspective on the studied relationship.

\section{Conclusions}

Higher egg intake may be associated with the overall unhealthy dietary habits, which is why the number of eggs consumed daily should not be considered an independent risk factor for elevated fasting glucose level. The clustering of dietary risk factors may thus explain higher risk of elevated FG observed in the group of men who consume a lot of eggs. 


\section{Supplementary information}

Supplementary information accompanies this paper at https://doi.org/10. 1186/s12937-019-0516-5

Additional file 1: Table S1. Comparison of the study group and the drop out group.

Additional file 2: Adult Semi-Quantitative Food Frequency Questionnaire.

\section{Abbreviations}

BMl: Body mass index; Cl: Confidence interval; CVD: Cardiovascular diseases; DP: Dietary pattern; FFQ: Food frequency questionnaire; FG: Fasting glucose; Me: Median; OR: Odds ratio; PURE Study: Prospective Urban and Rura Epidemiological Study; RR: Relative risk; SFA: Saturated fatty acids; T2DM: Type 2 diabetes mellitus

\section{Acknowledgements}

Not applicable.

\section{Authors' contributions}

$B R I$ and ACK have made substantial contributions to the conception and design of the study. KZ and AS have acquired and analyzed the data. ACK and DR have analyzed and interpreted the data. ACK has drafted the manuscript. BRI, DR, KZ and AS have critically revised the manuscript. All authors have read and approved the submitted version of the manuscript.

\section{Funding}

PURE Poland sub-study was funded by the Polish Ministry of Science and Higher Education (grant no. 290/W-PURE/2008/0). This study was funded by Wroclaw Medical University (grant no. STM.E110.17.019).

\section{Availability of data and materials}

The datasets used and/or analyzed during the current study are available from the corresponding author on reasonable request.

\section{Ethics approval and consent to participate}

All individuals were volunteers and signed an informed consent form before any study procedures were performed. The study was approved by the Polish Ethics Committee (No. KB-443/2006).

\section{Consent for publication}

Not applicable.

\section{Competing interests}

The authors declare that they have no competing interests.

\section{Author details}

'Department of Dietetics, Wroclaw Medical University, Parkowa 34, 51-616 Wrocław, Poland. ²Department of Social Medicine, Wroclaw Medical University, Wrocław, Poland. ${ }^{3}$ Department of Angiology, Hypertension and Diabetology, Wroclaw Medical University, Wrocław, Poland.

\section{Received: 29 May 2019 Accepted: 20 December 2019}

Published online: 30 December 2019

\section{References}

1. Kunachowicz H, Przygoda B, Nadolna I, Iwanow K. Tables of composition and nutritional value of food. Warsaw: PZWL; 2017.

2. Mensink RP, Zock PL, Kester AD, Katan MB. Effects of dietary fatty acids and carbohydrates on the ratio of serum total to $\mathrm{HDL}$ cholesterol and on serum lipids and apolipoproteins: a meta-analysis of 60 controlled trials. Am J Clin Nutr. 2003:77:1146-55

3. Yu E, Rimm E, Qi L, et al. Diet, lifestyle, biomarkers, genetic factors, and risk of cardiovascular disease in the nurses' health studies. Am J Public Health. 2016;106:1616-23.

4. Lichenstein $A H$, Appel $\sqcup$, Brands $M$, et al. Diet and lifestyle recommendations revision 2006. A scientific statement from the American Heart Association scientific committee. Circulation. 2006;114:82-96.

5. Graham I, Atar D, Borsch-Johnsen K, et al. European guidelines on cardiovascular disease prevention in clinical practice: executive summary.
Fourth joint task force of the European Society of Cardiology and Other societies on cardiovascular disease prevention in clinical practice. Eur Heart J. 2007;28:2375-414

6. 2015-2020 Dietary Guidelines for Americans 8th ed. Washington, DC: US Dept of Health and Human Services. http://health.gov/dietaryguidelines/2 015/guidelines/ Accessed 28.04.2019.

7. Jarosz M. Normy żywienia dla populacji polskiej - nowelizacja 2017. Warsaw: The Food and Nutrition Institute; 2017.

8. Araszkiewicz A, Bandurska-Stankiewicz E, Budzyński A, et al. 2019 Guidelines on the management of diabetic patients. A position of Diabetes Poland. Clin Diabet. 2019:8:1.

9. Djoussé L, Gaziano JM, Buring JE, Lee IM. Egg consumption and risk of type 2 diabetes in men and women. Diabetes Care. 2009:32:295-300.

10. Li Y, Zhou C, Zhou X, Li L. Egg consumption and risk of cardiovascular diseases and diabetes: a meta-analysis. Atherosclerosis. 2013;229:524-30.

11. Hu FB, Stampfer MJ, Rimm EB, et al. A prospective study of egg consumption and risk of cardiovascular disease in men and women. JAMA. 1999;21:1387e94.

12. Rong $Y$, Chen $L$, Zhu T, et al. Egg consumption and risk of coronary heart disease and stroke: dose-response meta-analysis of prospective cohort studies. BMJ. 2013:346:e8539.

13. Trichopoulou A, Psaltopoulou T, Orfanos P, Trichopoulos D. Diet and physical activity in relation to overall mortality amongst adult diabetics in a general population cohort. J Intern Med. 2006;259:583-91.

14. Djoussé L, Khawaja OA, Gaziano JM. Egg consumption and risk of type 2 diabetes: a meta-analysis of prospective studies. Am J Clin Nutr. 2016;103:474-80.

15. Hu FB. Dietary pattern analysis: a new direction in nutritional epidemiology. Curr Opin Lipidol. 2002;13:3-9.

16. Krebs-Smith SM, Subar AF, Reedy J. Examining dietary patterns in relation to chronic disease. Matching measures and methods to questions of interest. Circulation. 2015;132:790-3

17. Suliga $E$, Kozieł $D$, Cieśla $E$, et al. Dietary patterns in relation to metabolic syndrome among adults in Poland: a cross-sectional study. Nutrients. 2017:9:1366.

18. Corsi DJ, Subramanian SV, Chow CK, et al. Urban Rural Epidemiology (PURE) study: Baseline characteristics of the household sample and comparative analyses with national data in 17 countries. Am Heart J. 2013;166:636-46.e4.

19. Dehghan $M$, llow $R$, Zatonska $K$, et al. Development, reproducibility and validity of the food frequency questionnaire in the Poland arm of the prospective urban and rural epidemiological (PURE) study. J Hum Nutr Diet. 2012;25:225-32.

20. Szponar L, Wolnicka K, Rychlik E. Album photographs of food products and dishes. Warsaw: The Food and Nutrition Institute; 2000.

21. Ardisson Korat AV, Willett WC, Hu FB. Diet, lifestyle, and genetic risk factors for type 2 diabetes: a review from the nurses' health study, nurses' health study 2, and health professionals' follow-up study. Curr Nutr Rep. 2014;3:345-54.

22. Nguyen NT, Nguyen XM, Lane J, Wang P. Relationship between obesity and diabetes in a US adult population: findings from the National Health and nutrition examination survey, 1999-2006. Obes Surg. 2011;21:351-5.

23. Darani Zad N, Mohd Yusof R, Esmaili H, Jamaluddin R, Mohseni F. Association of dietary pattern with biochemical blood profiles and bodyweight among adults with type 2 diabetes mellitus in Tehran. Iran J Diabetes Metab Disord. 2015;14:28.

24. Malik VS, Fung $T$, van Dam RM, Rimm EB, Rosner B, Hu FB. Dietary patterns during adolescence and risk of type 2 diabetes in middle-aged women. Diabetes Care. 2012:35:12-8.

25. Jannasch F, Kröger J, Schulze MB. Dietary patterns and type 2 diabetes: a systematic literature review and meta-analysis of prospective studies. J Nutr. 2017;147:1174-82.

26. Walsh El, Jacka FN, Butterworth P, Anstey KJ, Cherbuin N. The association between Western and prudent dietary patterns and fasting blood glucose levels in type 2 diabetes and normal glucose metabolism in older Australian adults. Heliyon. 2017;3:e00315.

27. Atkinson FS, Foster-Powell K, Brand-Miller JC. International tables of glycemic index and glycemic load values: 2008. Diabetes Care. 2008;31:2281-3.

28. Woo HW, Choi BY, Kim MK. Cross-sectional and longitudinal associations between egg consumption and metabolic syndrome in adults $\geq 40$ years old: the Yangpyeong cohort of the Korean genome and epidemiology study (KoGES_Yangpyeong). PLoS One. 2016;11:e0147729.

29. Shin S, Lee HW, Kim CE, Lim J, Lee JK, Lee SA, Kang D. Egg Consumption and Risk of Metabolic Syndrome in Korean Adults: Results from the Health Examinees Study. Nutrients. 2017;9:pii: E687. 
30. Park S-J, Jung J-H, Choi S-W, Lee H-J. Association between egg consumption and metabolic disease. Korean J Food Sci Anim Resour. 2018;38:209-23.

31. Heidemann C, Scheidt-Nave C, Richter A, Mensink GB. Dietary patterns are associated with cardiometabolic risk factors in a representative study population of German adults. Br J Nutr. 2011;106:1253-62.

32. Labonté MĖ, Dewailly E, Lucas M, Chateau-Degat ML, Couture P, Lamarche B. Traditional dietary pattern is associated with elevated cholesterol among the Inuit of Nunavik. J Acad Nutr Diet. 2014;114:1208-15.e3.

33. Machado Arruda SP, da Silva AA, Kac G, et al. Dietary patterns are associated with excess weight and abdominal obesity in a cohort of young Brazilian adults. Eur J Nutr. 2016;55:2081-91.

34. Naja F, Hwalla N, Itani L, Karam S, Sibai AM, Nasreddine L. A Western dietary pattern is associated with overweight and obesity in a national sample of Lebanese adolescents (13-19 years): a cross-sectional study. Br J Nutr. 2015; 114:1909-19.

\section{Publisher's Note}

Springer Nature remains neutral with regard to jurisdictional claims in published maps and institutional affiliations.

Ready to submit your research? Choose BMC and benefit from:

- fast, convenient online submission

- thorough peer review by experienced researchers in your field

- rapid publication on acceptance

- support for research data, including large and complex data types

- gold Open Access which fosters wider collaboration and increased citations

- maximum visibility for your research: over $100 \mathrm{M}$ website views per year

At BMC, research is always in progress.

Learn more biomedcentral.com/submissions 